\title{
Function and Therapeutic Potential of Mesenchymal Stem Cells and Their Acellular Derivatives on Non-Healing Chronic Skin Ulcers
}

Victor Alfonso Solarte', Silvia Becerra-Bayona', Lissette Sánchez-Aranguren ${ }^{2}$, Claudia L. Sossa ${ }^{1,2}$, Alvaro Meana ${ }^{3,4}$, Jesus Merayo-Lloves ${ }^{3,4}$ and Martha L. Arango-Rodríguez ${ }^{2 *}$

1 Universidad Autónoma de Bucaramanga (UNAB), 681004153 Bucaramanga, Colombia

${ }^{2}$ Banco Multitejidos y Centro de Terapias Avanzadas, Fundación Ofalmológica de Santander, Clínica Carlos Ardila Lulle (FOSCAL), 681004153 Floridablanca, Colombia

${ }^{3}$ Instituto Oftalmológico Fernández-Vega, Fundación de Investigación Oftalmológica, Universidad de Oviedo, Oviedo, Spain

${ }^{4}$ U714 Centre for Biomedical Network Research on Rare Diseases (CIBERER), Oviedo, Spain

\begin{abstract}
Non-healing chronic skin ulcers are considered a major biological, psychological, and financial burden for both patients and health systems. Multidisciplinary endeavors are required to address this refractory disease, in order to find definitive solutions that lead to improved living conditions. Diabetes, venous stasis, arterial insufficiency, pressure and radiation are common risk factors associated with chronic wounds. Unfortunately, the cured state for these wounds has a high relapse rate, which adversely affects the patient's quality of life. Nevertheless, advances on regenerative medicine have allowed the development of cell-based therapies that promote wound healing by increasing cell migration and differentiation. Particularly, mesenchymal stem cells (MSCs) and their acellular derivatives have emerged as an attractive therapeutic agent in various diseases, including chronic skin ulcers, due to their role in immunomodulation and tissue regeneration. In this review discusses the characteristics of MSCs as well as their regenerative properties and their action mechanisms on wound healing. Finally, the perspectives of MSCs and their acellular derivatives in clinical chronic skin ulcer therapy are also explored.
\end{abstract}

Keywords: Mesenchymal Stem Cells; Acellular derivatives; Regenerative medicine; Chronic skin ulcers

\section{Introduction}

The skin is an important organ that effectively protects the body from the outside environment. This organ has developed intrinsic mechanisms that not only defend the organism from a wide range of external threats, such as bacteria, xenobiotic substances and dehydration, but also enable rapid restoration of tissue integrity and organ-specific function. Indeed, when a degloving injury occurs, the body initiates a series of complex events to recover skin protection. A normal cutaneous wound healing process is divided into sequential and overlapping phases that include early and late events. The initial events involve homeostasis, immediate inflammatory response (infiltration of cytokine-releasing leukocytes with antimicrobial functions), as well as cell proliferation and migration to form new epithelium, blood vessels, and extracellular matrix (ECM). In the late stage, the wound contracts as the ECM is remodeled [1].

In order to achieve the most favorable repair, at each wound healing phase, different cell types, specific cytokines, chemokines and growth factors must interact at the target site with their respective receptors, growth factors, and ECM components [2]. These highly regulated cellular, humoral and molecular processes have been described as an orchestral performance that leads to perfect regeneration; however, human adult wounds usually undergo a repair process that leads to scarring, and, in some cases, to non-healing chronic wounds [3].

Non-healing chronic wounds are characterized by a loss of epidermal and dermal tissue, as well as pathologically extensive inflammation. They are more frequently found in ageing patients, or in those suffering from conditions such as obesity, chronic disease, vascular insufficiency, diabetes, and malnutrition. Additionally, chronic wounds are affected by local factors, including hypoxia, ischemia-reperfusion, injury, pressure, bacterial colonization and edema, which play a major role in the disruption of the normal wound healing cascade [4,5]. In wounds for which the repair process has been disrupted, a sustained anatomical and functional progress is not reached within an appropriate time frame (usually three months) and remain intractable despite adequate wound management [5].

Non-healing ulcers are considered a major burden for patients and their families. In fact, the incidence of wounds has been called the "silent epidemic" [6], due to the large impact they have on the life quality of over 40 million people worldwide [5], and the significant economic cost they represent for the health care system.

Patients suffering from non-healing ulcers report pain, loss of function, and infections that often lead to amputations or sepsis [6], in addition to the severe physical, mental and social consequences associated with this condition [7]. Currently available treatments for chronic wounds involve debridement, dressings, and antibiotics. Nevertheless, around $50 \%$ of chronic wounds are resistant to these therapies, even when using promising techniques such as chemicals, dressings and skin grafts $[8,9]$. Therefore, new strategies to stimulate skin regeneration may provide novel therapeutic approaches to reduce non-healing ulcer disease [2].

In this context, multipotent mesenchymal stromal cells, also referred to as mesenchymal stem cells (MSCs), have been explored as an attractive therapeutic agent to treat non-healing ulcers [10].

*Corresponding author: Martha Ligia Arango-Rodríguez, Banco Multitejidos y Centro de Terapias Avanzadas, Fundación Ofalmológica de Santander, Clínica Carlos Ardila Lulle (FOSCAL), 681004153 Floridablanca, Colombia, Tel: 577-6382828 ext. 4022; E-mail: martha.arango@foscal.com.co

Received March 26, 2018; Accepted April 16, 2018; Published April 30, 2018

Citation: Solarte VA, Becerra-Bayona S, Sánchez-Aranguren L, Sossa CL, Meana A, et al. (2018) Function and Therapeutic Potential of Mesenchymal Stem Cells and Their Acellular Derivatives on Non-Healing Chronic Skin Ulcers. J Stem Cell Res Ther 8: 423. doi: 10.4172/2157-7633.1000423

Copyright: (c) 2018 Solarte VA, et al. This is an open-access article distributed under the terms of the Creative Commons Attribution License, which permits unrestricted use, distribution, and reproduction in any medium, provided the original author and source are credited. 
MSCs offer outstanding advantages over other stem cell populations: low immunogenicity, anti-inflammatory properties, and their culture and expansion in vitro is relatively simple. Moreover, MSC acellular derivatives could also be potentially used as a convenient therapeutic tool. The goal of this review was to highlight the features, function and action mechanism of MSCs in the context of repair and regeneration of wounds that are resistant to healing. Furthermore, relevant preclinical and clinical studies illustrating the impact of allogeneic and autologous MSCs obtained from different sources, as well as their derivatives on wound healing are exposed.

\section{Characteristics of MSCs}

\section{Tissue sources}

Bone marrow-derived MSCs (BM-MSCs) were first described by Alexander Friedenstein et al. [11] as adherent, fibroblast-like, clonogenic cells (colony forming unit-fibroblast, CFU-F), which possess high replicative capacity in vitro [11-13], are able to differentiate into several mesenchymal cell lineages (osteoblasts, chondrocytes and adipocytes), and support the hematopoietic stroma [11-15]. These pioneer studies demonstrated that BM contains a cell population distinct from haematopoietic stem cells, with stem cell features.

MSCs are a heterogeneous subset of stromal cells distributed throughout the stroma of almost all tissues/organs in vivo [16], giving rise to a variety of sources for their isolation, including adult peripheral blood, adipose tissue, BM, as well as fetal (e.g. umbilical cord blood, Wharton's jelly, amnion, amniotic fluid, and placenta) and embryonic tissues [16,17]. Despite the number of sources, most of the MSCs used for clinical trials are primarily derived from $\mathrm{BM}$, adipose tissue (AD), and umbilical cord blood (UCB) [17], being BM considered the gold standard [17]. Nonetheless, BM-MSC isolation involves a highly invasive aspiration procedure that often causes severe pain and high risk of infection [18]. Furthermore, limited volume of BM is collected at a time, resulting in a low MSC yield, which appears to be detrimental for MSC proliferation and differentiation potential, as indicated by the presence of senescence [19]. In an effort to overcome these obstacles, other MSC sources have been explored. MSCs derived from AD (ADMSCs) show similar morphology and phenotype as BM-MSCs, and offer the advantage of a less invasive isolation procedure. In fact, $\mathrm{AD}$ MSCs can be easily obtained from biological material generated during liposuction, lipoplasty or lipectomy [18]. Even though these cells are considered an excellent alternative to BM-MSCs in the context of innovative approaches for MSC treatments [19], the literature presents conflicting reports regarding the similarities between AD-MSCs and BM-MSCs. Although they share many biological characteristics, there are some differences in their immunophenotype, differentiation potential, transcriptome, proteome, and immunomodulatory activity $[20,21]$. These differences should be taken into account when selecting the MSC source to be used in research and for therapeutic purposes $[22,23]$.

To surmount the barriers associated with MSC precedence and isolation procedures, the use of cadaveric MSCs (CMSCs) from BM has recently emerged as a new approach. Mansilla and coworkers were the first research group that reported the use of CMSCs for treating severe thermal burns in a 26-year old male patient [24]. After isolation and expansion of CMSCs, combined treatment (conventional and CMSCs) was administered to the patient, who did not have any immunological rejection and was monitored during 35 days. The authors observed a faster growth of granulation dermal-like tissue and new epidermis compared to the control group (patients treated with conventional methods). After three years of follow-up, no adverse events were detected. This is the first time CMSCs were employed as a means for improving burn closures; nevertheless, additional studies to further demonstrate its safe use are indeed required.

\section{Isolation and expansion}

MSC-based therapies demand large cell numbers per treatment (hundreds of millions), which implies extensive expansion in vitro, since MSCs are scarce in the body even though they are present in several types of tissues [25]. The age and clinical characteristics of the MSC donors play an essential role in optimizing the cell culture conditions in order to scale-up the process for clinical applications [26]. Depending on the MSC source, different procedures have been used to perform MSC isolation. For instance, the most common method to isolate BM-MSCs is the density gradient procedure or the direct cell plating on a solid surface due to their adhesion capacity [27]. In contrast, AD-MSCs are obtained by enzymatic treatment (collagenase digestion) and centrifugation (density gradient separation) in order to collect the pre-adipocyte stromal vascular fraction and remove the adipocyte fraction [28].

After cell isolation, MSCs are typically expanded in monolayer culture on standard tissue dishes using basal medium that contains $10 \%$ fetal bovine serum (FBS) [29]. These cells display a spindle-shaped morphology during culture, retaining their stemness characteristics. Nevertheless, xenogeneic components have to be avoided in cell maintenance, and good manufacturing practice guidelines need to be followed in order to use these cells in cell-based therapy treatments. In this context, human platelet lysate has recently been proposed as a promising FBS substitute [30], and several authors have reported its higher influence on promoting MSC proliferation, relative to FBS [3134].

Cell seeding density is another essential parameter in MSC in vitro expansion, and it depends on the MSC source. For example, BM-MSCs are suggested to be seeded at $4-22 \times 10^{3} \mathrm{BM}$ mononuclear cells $/ \mathrm{cm}^{2}$, yielding up to $9.8 \times 10^{8} \mathrm{MSCs}$ when they are harvested after one passage $[35,36]$. In contrast, MSCs derived from UCB (UCB-MSCs) should be seeded at higher densities (around $1 \times 10^{6} / \mathrm{cm}^{2}$ ) because of their low quantity [35,37]. In the case of MSCs obtained from embryonic tissues, it has been suggested to use lower cell densities since they have higher proliferative capacity and life span, as well as higher differentiation potential and biological properties compared with MSCs derived from adult tissues [38].

On the other hand, the inconsistency found in the results of clinical studies reported in literature, may be due to in part to highly variable quality of MSCs, and more specifically, the lack of a robust manufacturing process. The latter does not allow the production of sufficient doses of MSCs with a bath-to-bath consistency. In consequence, recent studies have proposed the creation of a MSC bank by generating a pool of bone marrow mononuclear cells from multiple donors as a novel strategy, which may allow the patients to receive the same standardized MSC therapy in clinical studies $[39,40]$.

\section{Minimal criteria for MSC characterization}

The International Society for Cell Therapy lists the minimal criteria to define human MSCs [41]. First, MSCs must be plastic-adherent cells in standard culture conditions. Second, MSCs must be able to differentiate into chondrocytes, osteoblasts, and adipocytes in vitro. Third, MSCs must express CD29, CD73, CD90, CD44 and CD105, and lack expression of hematopoietic markers (CD14, CD34, CD45), 
endothelial markers (CD31), human leukocyte antigen (HLA) class II, costimulatory molecules (CD80, CD86), and HLA-DR surface molecules [42]. However, these markers may also vary among different MSC sources. For example, UCB-MSCs express CD45, CD14, and CD31 and lack the expression of CD34, CD1a, and CD80, expression profile that is quite different when BM-MSCs are studied [35,43].

\section{MSC delivery, homing and engraftment capacity}

Although it has been demonstrated that MSCs play a role in the wound healing process, there is not currently a recommended approach for delivering MSCs as a treatment for chronic wounds. The most common routes of MSC administration are intradermal (into the dermis) and subcutaneous (below the epidermis and dermis) injections into or around the wound site; however, topical MSC application to the wound, immediately covered with a dressing, is also used. In these methods, MSCs are usually suspended in sterile PBS and applied around the edges of the ulcer [44-46]. Indeed, some pre-clinical studies have shown MSC homing and engraftment on non-healing wounds by using these routes. In particular, Pratheesh et al. labeled caprine MSCs with PKH26 (a fluorescent dye that binds to the cell membrane) in order to track the grafted cells and investigate their direct action and migration pattern at the incisional wound site in rabbits [47]. After creating the incisional wounds and intradermally administering the PKH26-labeled cells, the authors found that the MSCs were trapped within both the hair follicles and the injured area close to the wounds. After 14 days, wounds were healed up and the red fluorescent dye was still present, indicating the integration of the labeled cells into the host skin and suggesting a synergic role in the wound healing process [47]. Likewise, Hanson et al. showed the presence of pig MSC DNA after 21 days of being intradermally applied to partial thickness cutaneous wounds in a porcine model [48]. Some other studies have also demonstrated that, after engraftment, MSCs start to migrate to the regenerated tissue [49].

In addition, MSC local administration has been also combined with different methods in order to improve their survival and proliferation at the wound site. Recently, Yu et al. utilized MSC administration in a full-thickness excisional wound rat model along with negative pressure wound therapy (values at continuous $-150 \mathrm{mmHg}$ ), for improving the viability of the MSCs and induce MSC differentiation into cutaneous tissue-related cell types. The results demonstrated that MSCs combined with negative pressure could significantly promote cutaneous wound healing, characterized by robust and improved vascularization at wound sites [50]. More importantly, the authors found that negative pressure provided a beneficial microenvironment supporting better MSC viability as well as inducing neoangiogenesis and maturation of blood vessels, suggesting that this strategy may serve as an alternative to soft tissue reconstruction for wound healing.

Several clinical studies have evidenced safety and efficacy of MSCs after local injection Table 1 [51-54]. In particular, Conget et al. evaluated the improvement of ulcers in two patients with recessive dystrophic epidermolysis bullosa (RDEB) by intradermally administering allogenic MSCs on intact and chronic ulcerated sites. After one week of the procedure, type VII collagen was detected in the MSC-treated ulcers along the basement membrane zone, as well as a continuous dermal-epidermal junction. Also, re-epithelialization of chronic ulcerated skin was observed only near MSC administration sites. Although the observed clinical benefits lasted for four months in both patients, the intradermal administration of allogeneic MSCs was associated with type VII collagen replenishment at the dermalepidermal junction, prevention of blistering and improvement of wound healing in unconditioned patients with RDEB [51]. Similarly, Dash et al. conducted a clinical trial with 24 patients with non-healing ulcers of the lower limb that was followed up for twelve months. The participants were randomly distributed into two groups: the implant and the control group. Both groups received standard wound dressings, but the first group also received autologous BM-MSCs. The authors reported that the implant group showed a significant improvement compared to the control group in terms of wound size, pain-free walking distance, and liver and renal function [52].

On the other hand, new MSC delivery methods, such as bioengineered scaffolds, have been developed to enhance cell engrafting capacity, and have become a promising strategy for wound repair [55]. Wang et al. prepared acellular dermal matrixes (ADM) from mice in which BM-MSCs were seeded and used in full-thickness wounds in mice. The mice treated with the ADM presented not only an accelerated wound healing process, but also improved blood vessel formation as well as re-epithelialization and appendage regeneration [55]. Similarly, available artificial dermal matrices, such as Integra, have been modified to behave as an ECM for MSC culture. Formigli et al. seeded BM-MSCs on Integra matrices pre-coated with platelet-rich plasma in order to optimize MSC engraftment on the wound area and elucidate the mechanism of MSC action in a full thickness model using rats [56]. The authors demonstrated that the MSC-seeded Integra matrix accelerated healing, promoted complete re-epithelization, induced hair follicle appearance, and enhanced blood vessel formation.

Another promising strategy for MSC delivery on wound tissues is the use of engineered microspheres as a skin substitute. Indeed, Huang et al. designed epidermal growth factor (EGF) microspheres on which BM-MSCs were seeded and then incorporated into a biomimetic scaffold for the generation of a skin construct [57]. After implanting these MSC-seeded-EGF microspheres into excisional wounds in mice, the healing rate was accelerated by increasing re-epithelialization and decreasing skin contraction. In addition, the data revealed the appearance of repaired sweat glands after 3 weeks of wound healing [57].

Despite the fact that, due to their remarkable intrinsic properties, MSCs are attractive for the treatment of non-healing wounds, there is still a lack of standardized routes and delivery methods to guarantee MSC optimal engraftment. Therefore, controlled studies may be required to investigate the appropriate approach to be used to deliver MSCs and ensure their survival at the wound site.

\section{MSC oxidative stress management}

MSCs are characterized by their ability to tolerate ex vivo culture and ionizing radiation, two conditions that generate strong oxidative stress (OS) [58,59]. In this context, MSCs prove to be useful in the treatment of pathologies that provoke tissue damage such as acute myocardial infarction [60], cerebral ischemia [61], and diabetes [62]. Specifically, Conget et al. showed that human BM-MSCs are highly resistant to OS-induced death [63]. This low susceptibility to reactive species correlates with the ability of human BM-MSCs to effectively scavenge peroxide and peroxynitrite, being the latter associated with the constitutive expression and activity of superoxide dismutase (SOD1, SOD2), catalase, glutathione peroxidase 1 enzymes and the high level of intracellular total glutathione (GSx) $[62,63]$. Furthermore, human BM-MSCs expressed constitutively and at a high level methionine sulfoxide reductase A, a crucial enzyme for the repair of oxidized proteins and for the recovery of methionine residues that act as oxidant scavengers $[63,64]$. Likewise, it has also been reported that human BM-MSCs produce the enzymes required for DNA repair [65]. 
Citation: Solarte VA, Becerra-Bayona S, Sánchez-Aranguren L, Sossa CL, Meana A, et al. (2018) Function and Therapeutic Potential of Mesenchymal Stem Cells and Their Acellular Derivatives on Non-Healing Chronic Skin Ulcers. J Stem Cell Res Ther 8: 423. doi: 10.4172/2157-7633.1000423

Page 4 of 14

\begin{tabular}{|c|c|c|c|c|c|c|c|}
\hline Author & MSC source & Wound model & Used model & Delivery method & $\begin{array}{l}\text { Time of study } \\
\text { (days) }\end{array}$ & Mechanism of action & Therapeutic effect \\
\hline Rustad KC [45] & Goat(BM) & Full thickness & Rabbit & Intradermally & 14 & Graftment & Complete healing \\
\hline Nie C [46] & Pig (BM and AT) & $\begin{array}{l}\text { Partial } \\
\text { thickness }\end{array}$ & $\mathrm{Pig}$ & Intradermally & 21 & Graftment & $\begin{array}{l}\text { Appearance } \\
\text { Re-epithelialization } \\
\text { Epidermal maturation }\end{array}$ \\
\hline Dash NR [52] & Mouse (BM) & Full thickness & Mouse & $\begin{array}{l}\text { Acellular dermal } \\
\text { matrix }\end{array}$ & 21 & Graftment and migration & $\begin{array}{l}\text { Neovascularization } \\
\text { Skin appendage regeneration } \\
\text { Re-Eithelialization }\end{array}$ \\
\hline $\begin{array}{l}\text { Yoshikawa T } \\
\text { [53] }\end{array}$ & $\begin{array}{l}\text { Rabbit } \\
\text { (BM and AT) }\end{array}$ & Full thickness & Rabbit & Intradermally & 21 & No reported & $\begin{array}{l}\text { Re-epithelialization } \\
\text { Collagen deposition } \\
\text { Restoration of skin architecture } \\
\text { Inflammatory infiltration }\end{array}$ \\
\hline Mansilla E [24] & Human (CBM) & Burn & Clinical trial & $\begin{array}{l}\text { Sprayed with } \\
\text { fibrinogen }\end{array}$ & 35 & $\begin{array}{l}\text { Graftment and } \\
\text { differentiation }\end{array}$ & Granulation dermal-like tissue \\
\hline Falanga V [54] & Rat (BM) & Full thickness & Rat & $\begin{array}{l}\text { Artificial dermal } \\
\text { matrix }\end{array}$ & 28 & Paracrine signaling & $\begin{array}{l}\text { Re-epithelialization } \\
\text { Neoangiogenesis } \\
\text { Return of hair follicles } \\
\text { Collagen deposition }\end{array}$ \\
\hline Wang Q [55] & Human (UC) & Burn & Rat & Tail vein injection & 21 & Migration & $\begin{array}{l}\text { Wound closure } \\
\text { Neo-vascularization } \\
\text { Ratio of Collagen I/III } \\
\text { Inflammatory responsec }\end{array}$ \\
\hline Formigli L [56] & Dog (BM) & Full thickness & Canine & Intradermally & 35 & Paracrine signaling & $\begin{array}{l}\text { Wound closure } \\
\text { Collagen synthesis } \\
\text { Cell proliferation } \\
\text { Angiogenesis } \\
\text { Cytokine Eroduction }\end{array}$ \\
\hline Huang SP [57] & Human (BM) & Full thickness & Rat & Biomatrix & 7 & $\begin{array}{l}\text { Graftment and paracrine } \\
\text { signaling }\end{array}$ & $\begin{array}{l}\text { Wound closure } \\
\text { Re-epithelialization } \\
\text { Neovascularization } \\
\text { Granulation tissue formation } \\
\text { Immune cell infiltration } \\
\text { Giant cell formation }\end{array}$ \\
\hline Halliwell B [58] & Mouse (BM) & Burn & Mouse & Transfusion & 28 & Migration & Re-epithelialization \\
\hline Chen MF [59] & Mouse (BM) & Full thickness & Mouse & Microspheres & 21 & $\begin{array}{l}\text { Differentiation and } \\
\text { paracrine signaling }\end{array}$ & $\begin{array}{l}\text { Re-epithelialization } \\
\text { Sweet-glands like structures skin } \\
\text { contractions }\end{array}$ \\
\hline Le Blanc K [42] & Mouse (AT) & Full thickness & Mouse & $\begin{array}{l}\text { Extracellular matrix } \\
\text { Eatch }\end{array}$ & 14 & Paracrine signaling & Wound healing rate Fibrosis \\
\hline Mareschi K [43] & Mouse (BM) & Full thickness & Mouse & Hydrogel & 28 & Engraftment & Skin appendages Angiogenesis \\
\hline Chen SL [60] & $\operatorname{Dog}(\mathrm{AT})$ & Full thickness & Mouse & Intradermally & 21 & $\begin{array}{l}\text { Differentiation and } \\
\text { paracrine signaling }\end{array}$ & $\begin{array}{l}\text { Wound closure } \\
\text { Neovascularization } \\
\text { Regeneration of skin appendages }\end{array}$ \\
\hline Kurozumi K [61] & Rat (AT) & Full thickness & Rat & Intradermally & 9 & No reported & $\begin{array}{l}\text { Wound healing } \\
\text { Density of fibroblasts }\end{array}$ \\
\hline Lam MT [44] & Rat (AT) & Full thickness & Rat & Intradermally & 28 & Differentiation & $\begin{array}{l}\text { Epithelialization } \\
\text { Granulation tissue deposition } \\
\text { Time for wound closure }\end{array}$ \\
\hline Hanson SE [48] & Human (BM) & Ulcerated sites & Clinical trial & Intradermally & 7 & No reported & $\begin{array}{l}\text { Re-epithelialization } \\
\text { Replenishment of collagen VII at } \\
\text { the dermal-epidermal junction }\end{array}$ \\
\hline Ouma GO [49] & Human (BM) & $\begin{array}{l}\text { Diabetic foot } \\
\text { ulcers }\end{array}$ & Clinical trial & Intramuscularly & 84 & No reported & $\begin{array}{l}\text { Pain-free walking distance } \\
\text { Ulcer size }\end{array}$ \\
\hline Lee RH [62] & Mouse (BM) & Full thickness & Mouse & Tail vein injection & 14 & $\begin{array}{l}\text { Migration and } \\
\text { differentiation }\end{array}$ & $\begin{array}{l}\text { Wound size } \\
\text { Wound repair }\end{array}$ \\
\hline $\begin{array}{l}\text { Valle-Prieto A } \\
\text { [63] }\end{array}$ & Mouse (BM) & Full thickness & Mouse & Intradermally & 28 & $\begin{array}{l}\text { Differentiation and } \\
\text { paracrine signaling }\end{array}$ & $\begin{array}{l}\text { Wound closure } \\
\text { Re-epithelialization } \\
\text { Cellularity } \\
\text { Angiogenesis } \\
\text { Skin appendages }\end{array}$ \\
\hline Conget $\mathrm{P}$ [51] & Human (BM) & Acute wounds & Clinical trial & Fibrin polymer spray & 84 & Paracrine signaling & $\begin{array}{l}\text { Pain relief } \\
\text { Resurfacing } \\
\text { Wound size }\end{array}$ \\
\hline
\end{tabular}

Table 1: Pre-clinical and clinical studies that evidence the the safety and efficacy of MSCs after local administration. 


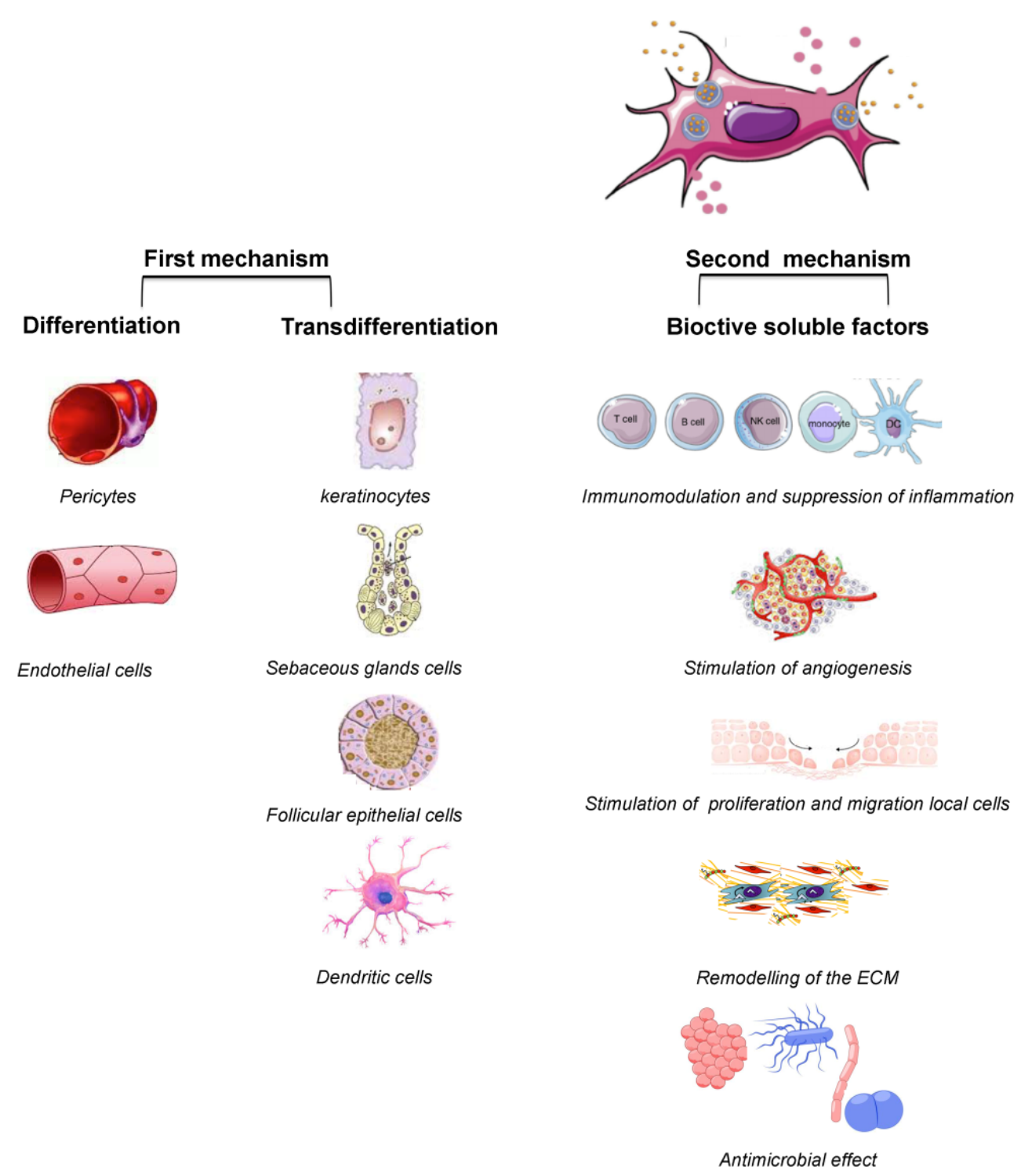

Figure 1: Mechanisms by which MSCs ameliorate skin damage. Three mechanisms might explain the therapeutic effect of MSCs. The first mechanisms includes the MSC differentiation into pericytes and endothelial cells and/or transdifferentiation into dermal and epidermal cells (keratinocytes, sebaceous glands cells, follicular epithelial cells and dendritic cells). The second mechanisms involves the MSC production of bioactive soluble factors which contribute to wound repair and regeneration by: i) immunomodulating and suppressing inflammation, ii) stimulating angiogenesis, proliferation and migration of local keratinocytes and dermal fibroblasts, iii) aiding in the formation and remodeling of the ECM, and iv) providing an antimicrobial effect. The third mechanisms involves the MSC transfer orgallellas (mitochondria transfer).

Cumulatively, human BM-MSCs possess the main enzymatic and nonenzymatic mechanisms for reactive species detoxification as well as proteome and genome oxidative damage repair, which ensure efficient OS management.

\section{Role of metabolism in MSC self-renewal}

In BM, MSCs reside under a hypoxic environment [66], with oxygen $\left(\mathrm{O}_{2}\right)$ tensions $\left(\mathrm{PO}_{2}\right)$ ranging from 10-32 $\mathrm{mmHg}$ [67]. The low $\mathrm{O}_{2}$ levels of the MSC niche promote the activation of hypoxia-inducible factor (HIF) dependent pathways, which regulate the metabolic fate and pluripotency of MSCs [68]. In general, hypoxia triggers adaptive responses to reduced $\mathrm{PO}_{2}$, enhancing the ability of cells to survive under $\mathrm{O}_{2}$ deprivation [69]. This effect is mediated by the transcription of HIF-1a controlled genes, including vascular endothelial growth factor (VEGF), which promotes the formation of new blood vessels [70] and erythropoietin, a hormone involved in red cell production. This in turn favors $\mathrm{O}_{2}$ tissue delivery [69] and the activation of glycolytic gene promoters [71]. The metabolic features of MSCs have been tested in vitro, demonstrating that culture of MSCs in normoxia share similar metabolic responses to reduced $\mathrm{PO}_{2}$ [72], with a concomitant metabolic plasticity of the MSC mitochondria [66]. Essentially, Pattappa, et al. showed that oxidative phosphorylation (OXPHOS) in MSCs cultured in normoxia accounts for at least $30 \%$ of total ATP production. OXPHOS dependence in vitro has been previously associated with increased reactive oxygen species (ROS) production and premature senescence of expanding MSCs [73], which can affect MSC overall therapeutic 
efficacy [72]. Thus, the ability of MSCs to retain their hypoxic signals in culture is an important feature to maintain their stem cell properties in vitro [72].

When compared to differentiated progeny, the MSC metabolic profile exhibits higher levels of glycolytic enzymes and lactate production [74], with diminished levels of OXPHOS proteins [75]. This demonstrates that undifferentiated BM-MSCs mainly rely on glycolysis for energy purposes, relative to their derived-differentiated cells (e.g. osteoblasts) [75]. Differentiation of expanding MSCs in vitro involves a metabolic switch that favors OXPHOS over glycolysis [75]. This effect on early-differentiated MSC metabolism redirects cell fate by increasing the expression of OXPHOS proteins, oxygen consumption rates, intracellular ATP levels [76], and mitochondrial ROS production [77]. As demonstrated before, hypoxic preconditioning in MSC culture enhanced MSC ability to maintain cell self-renewing properties after transplantation [78]. The effects of maintaining a hypoxic environment during MSC culture involved HIF-1a stabilization, which triggered increased growth factor production, including VEGF and its receptor Flk-1, insulin-like growth factor 1 (IGF-1) and basic fibroblastic growth factor (bFGF), as well as reduced pro-inflammatory molecule release $[72,79]$. Together, the improved production of these protective molecules enhanced the MSC abilities for tissue regeneration and self-renewal. Similarly, another key factor to sustain MSC renewal potential involves an increased glycolytic metabolism, which has been successfully proven during MSC high-glucose culture in vitro [80]. As a result, the role of glucose has been previously recognized as a key approach to enduring cell survival and function after construct transplantation [80].

\section{Role of MSCs in OS-related diseases}

The observed therapeutic effects after MSC transplantation into individuals with OS-related diseases might be attributed, among other mechanisms, to their potential to effectively scavenge exogenous ROS and reactive nitrogen species, once homed into the niche of damaged tissues. Indeed, mice with experimental diseases (liver and neurodegenerative diseases) that received MSCs showed a discrete but statistically significant lower ratio of reduced GSx to oxidized GSx [81], as well as a lower increase of disease-induced oxidative markers [82].

In particular, the surroundings of diabetic foot ulcers are characterized by a high-glucose environment, along with an extremely anoxic microenvironment [83]. These two conditions lead to increased production of pro-inflammatory molecules such as tumor necrosis factor alpha (TNF- $\alpha$ ), which subsequently enhance local inflammatory responses and thus result in wound healing disorders [84]. In animal studies, the presence of a high glucose microenvironment affects the vascular regeneration of skin ulcers in comparison to low glucose surrounding environments [83-85]. However, one of the key characteristics in successful MSC transplantation for treating diabetic foot ulcers relies on the ability of MSCs to sustain vascularization and angiogenesis. Based on this, there is a need for modulation of cell metabolic responses to the microenvironment surrounding diabetic foot ulcers, in order to control the MSC paracrine effects and cell survival, which might be accomplished by regulating nutrient bioavailability and intrinsic cellular metabolic pathways as well as using pharmacological approaches. A comprehensive understanding of the metabolic features that regulate and control stem cell fate during ulcer regeneration will provide a powerful tool to overcome the challenge of maintaining cell proliferation and differentiation in the hostile environment of chronic ulcers, where excessive inflammation prevents healing.

\section{Clinical Potential of MSCs}

Due to their intrinsic properties and regenerative capacity, MSCs are considered to have therapeutic potential, which makes them a favorable candidate for cell-based therapies and tissue engineering applications [86]. MSCs are able to migrate to the exact site of injury, differentiate into various cell lineages, and secrete abundant soluble growth factors and cytokines that are crucial for cell survival, proliferation, as well as host immune response modulation [87]. As a result, MSCs show a remarkable potential for the treatment of a number of diseases, including both immunological and non-immunological disorders. In particular, more than 756 clinical trials involving the use of MSCs are currently in progress (www.clinicaltrials.gov). These include the treatment of different conditions such as: myocardial infarction, osteogenesis imperfecta, hematologic malignancies, graft-versus-host disease, Crohn's disease, spinal cord injury, multiple sclerosis, and diabetes (for the healing of refractory wounds), without any reported serious adverse events [88]. Cumulatively, the results of these earlyphase studies indicate that the use of autologous and allogenic MSCs obtained from different sources appears to be safe. Nonetheless, the efficacy of these treatments remains to be demonstrated in late-stage clinical trials [87].

\section{Molecular mechanisms associated with the clinical potential of MSCs}

The therapeutic effects of MSCs to repair injured tissues have been largely associated to three mechanisms: i) differentiation or transdifferentiation into functional cells, ii) paracrine signals and iii) transfer of organelles and molecules to cells in the injury sites (Figure 1) [89]. In brief, the mechanisms through which MSCs could potentially enhance tissue repair are described below.

Cell differentiation and/or trans-differentiation: this mechanism includes the migration of MSCs to injury sites after administration in response to chemotactic signals in vivo [45]. Once MSCs are located at these sites, they start to engraft, differentiate and/or trans-differentiate to actively participate in tissue regeneration $[89,90]$. However, recent studies have suggested that MSC differentiation and/or transdifferentiation could be limited due to poor engraftment [91].

Paracrine signals: the production of bioactive soluble factors that modulate immune responses at injury sites has been suggested to contribute into the MSC therapeutic potency by promoting proliferation, migration and gene expression in several cell types $[92,93]$. These factors include cytokines, growth factors, enzymes, microparticles, miRNA and exosomes that are secreted without a direct cell-to-cell interaction. Also, it has been recently considered that MSCs could transfer their contents such as proteins and peptides, lipids, nucleic acids, and calcium and magnesium ions to local recipient cells at injury sites to stimulate cell survival and potentiate clinical responses [89,92,94-96].

Transfer of organelles: some studies have suggested that other paracrine mechanisms may play a part on cell signaling communication, mediated by cell-to-cell contacts by using tunneling nanotubes (TNTs) or cytonemes [97].

Cell-to-cell communication through highly dynamic TNTs, was described 40 years ago as a result of sea urchin cell studies [98]. At present, different authors have reported that MSCs may modulate cell responses by vesicle trafficking through TNTs. In particular, some authors have demonstrated MSC mitochondria transfer to several different cell types, including epithelial cells, endothelial cells, and 
cardiac myocytes [96-100]; as a result, intracellular mitochondrial transfer has been lately proposed as a potential molecular mechanism of MSC-induced therapeutic potential. Spees et al. showed trafficking of MSC mitochondria when these were co-cultured with injured lung epithelial cells (lacked functional mitochondria), which allowed lung cells to restore aerobic respiration and enhance cell growth [96]. Similarly, it was evidenced that MSCs rescued injured endothelial cells in vitro using an ischemia-reperfusion model via TNT-mediated mitochondrial transfer [100].

The efficient mitochondrial transfer between MSCs and mitochondrial-deficient cells has been showed to be dependent on TNT formation. Li et al. showed that human-induced pluripotent stem cell-derived MSCs transfer their functional mitochondria to airway epithelial cells that were exposed to cigarette smoke (chronic obstructive pulmonary disease) through the formation of TNTs using a rat model [101]. Similarly, Jiang et al. reported that TNT formation induced corneal protection to corneal epithelial cells via mitochondrial donation through the Rot/NF- $\kappa \mathrm{B} / \mathrm{TNF} \alpha \mathrm{ip} 2$ signaling pathway [102]. The effective transfer of mitochondria from MSCs to somatic cells could potentially abrogate associated mitochondrial-dysfunction damage in several pathological diseases. Nonetheless, the potential transfer of this organelle from MSCs to cells located at the wound injury sites still remain to be widely studied.

\section{MSC-based therapy for chronic wound healing}

Currently, MSC-based therapy for treating non-healing chronic wounds has shown supportive results. Particularly, a variety of clinical trials have revealed that MSCs are safe and therapeutic for healing chronic wounds [54], limb ischemia [103], diabetic foot ulcers [83] and radiation burns [104]. These studies reported that the administration of MSCs produced a significant recovery that entailed increased perfusion, decreased pain, ulcer size reduction, modulation of the radiation inflammatory processes, and a more appropriate wound repair. Specifically, the effect of MSCs on chronic wound healing is primarily reflected on the repair and replacement of cellular substrates, as well as the increased wound closure rates, tensile strength and angiogenesis. In addition, the use of MSCs allows to decrease scarring, attenuate inflammation, enhance migration of reparative cells and improve histological characteristics, such as superior rete ridge architecture, multilayered structure, major dermal-epidermal junction and the formation of new skin appendage structures (hair follicles and sebaceous glands) [105-109].

MSCs have the unique ability to initiate different wound-healing programs depending on the environmental milieu. Nevertheless, the exact mechanisms by which MSCs ameliorate skin damage are still under debate. In fact, two theories might explain the therapeutic effect of MSCs: MSC differentiation and/or transdifferentiation into dermal and epidermal cells and MSC production of bioactive soluble factors (growth factors, cytokines and specific proteins) Figure 1 [110]. Most studies agree on the fact that, although MSCs can migrate to injury sites in response to chemotactic signals in vivo [45], only a small percentage of the engrafted MSCs becomes incorporated and survives within the damaged tissue [111]. Also, several studies have evidenced that the implantation time of MSCs is usually too short to have an effective impact [112]. Indeed, it has been reported that less than $1 \%$ of MSCs survive more than one week in the wound site after systemic administration $[113,114]$. In contrast, other studies indicate that transplanted MSCs do not necessarily have to be in close proximity to the damaged tissue in order to promote wound repair and functional recovery, since the secretion of paracrine factors appears to be the main
MSC therapeutic action involved in skin disorder repair [115,116].

First theory: the role of MSC differentiation and transdifferentiation in chronic non-healing wounds: Different preclinical and clinical studies have described that MSCs help to restore the normal function of chronic wounds by: i) differentiating into pericytes $[45,110]$ and endothelial cells (ECs) $[45,105,106,110]$, and ii) transdifferentiating into keratinocytes, sebaceous glands cells, follicular epithelial cells and dendritic cells Table $1[64,105,110,117,118]$. Various studies have reported the differentiation of MSCs into EC lineage after their delivery at the ulcer sites. These cells expressed endothelial-type markers, such as Von Willebran Factor (vWF), Vascular Endothelial Growth Factor Receptor-2 (VEGFR-2), Vascular Cell Adhesion Molecule (VCAM), and helped to stabilize and promote the formation of new vessel walls. Huang et al. observed that AD-MSCs enhanced wound healing in full-thickness defects in mice by promoting greater invasion of blood vessels, relative to the control. Also, the grafted cells were positive stained for VEGF and vWF after transplantation in mice, suggesting that MSCs might promote angiogenesis by differentiating into ECs [57]. These findings are supported by the ability of MSCs to differentiate into mesoderm cells and transdifferentiate into endoderm functional cells, depending on culture conditions. Indeed, placenta-derived MSCs undergo in vitro differentiation into ECs, which is evidenced by expression of specific endothelial cell markers such as vWF, CD31 and VE-cadherin, after being exposed to several inducers during 10 days [106]. On the other hand, $\mathrm{Hu}$ et al. suggested that BM-MSCs migrated to the wound site and enhanced epithelialization by transdifferentiation into keratinocytes. They used a chimeric mouse model by inserting fluorescently-labeled male MSCs into a female mouse. The results showed that Y-chromosome positive MSCs were co-localized with pancytokeratin-positive cells, revealing self-transdifferentiation or cell fusion into keratinocytes [119]. Nevertheless, a study conducted by Sasaki et al. demonstrated that transdifferentiation of BM-MSCs into keratinocytes was not a result from spontaneous cell fusion; instead, the fluorescently-labeled male MSCs contained XY chromosomes, indicating that cell fusion was a rare event [110]. In contrast, other authors have reported conflicting data regarding MSC transdifferentiation capacity [120]. Rustad et al. assessed the in vivo differentiation of engrafted BM-MSCs after 14 days of wound healing in mice, and showed their capacity to differentiate into pericytes and ECs but not into keratinocytes [45]. Similarly, Formigli et al. showed that BM-MSCs did not transdifferentiate into keratinocytes, but instead promoted the differentiation of neighboring cells [56]. That said, the transdifferentiation process may depend on the wound microenvironment as well as the delivery system used to administer the MSCs, which might indicate their potential role in the wound healing process.

Despite the fact that MSC differentiation and transdifferentiation might play a critical role in wound healing, a number of studies have revealed poor MSC engraftment when they are injected in the wounds $[56,121]$. In this context, Wu et al. demonstrated by means of a tracing assay that injected BM-MSCs disappeared in the first 24 hours after delivery into dermal fibrotic skin regions in mice. Similar results were reported by Formigli et al., who studied BM-MSC grafting in rats. As a result, several authors have implied that the secretion of paracrine factors is the major MSC therapeutic mechanism involved in skin ulcer repair [79,122-124].

Second theory: MSC production of bioactive soluble factors: MSC acellular derivatives are defined as the set of factors/molecules secreted by MSCs to the extracellular space. These factors include trophic 
factors, soluble proteins, chemokines, cytokines, glycosaminoglycans, free nucleic acids, lipids, and extracellular vesicles (apoptotic bodies, microparticles and exosomes) [125].

Several groups have reported successful wound healing of surgical wounds [122,126], diabetic wounds [107,124] and burns [127-129] after the delivery of MSC acellular derivatives [129]. The effective wound healing has been associated with the secretion of trophic factors, such as VEGF, IGF-1, bFGF, platelet-derived growth factor BB (PDGF$\mathrm{BB}$ ), angiopoietin 1 (Ang-1), stromal cell-derived factor 1 (SDF-1), EGF, and keratinocyte growth factor (KGF), as well as the secretion of matrix metalloproteinase 9 (MMP9), and cytokines, including tumor necrosis factor beta 1 (TGF- $\beta 1$ ), interleukin 6 (IL-6) and IL8. These molecules contribute to wound repair and regeneration by: i) immunomodulating and suppressing inflammation, ii) stimulating angiogenesis, proliferation and migration of local keratinocytes and dermal fibroblasts, iii) aiding in the formation and remodeling of the ECM [118], and iv) providing an antimicrobial effect [130].

Immunomodulation and suppression of inflammation: MSCs have an immunomodulatory effect by mediating the proliferation, activation and function of immune cells since they typically have a low expression of the major histocompatibility complex (MHC) class I and lack the expression of MHC class II, CD40, CD80, and CD86. This allows MSCs to avoid T cell recognition, and often results in the absence of an immune response [131]. Indeed, pre-clinical studies have shown a suppressive effect on both the innate and adaptive immune response when MSCs are applied [132-134]. MSCs play a role in several phases of the immune response through the production of different soluble factors, especially in the phases of antigen recognition and presentation, T cell activation, proliferation, and differentiation as well as the effector stage of T cells [135]. In particular, MSCs produce factors such as TGF- $\beta 1$, hepatocyte growth factor (HGF), IGF- 1 , prostaglandin E2 ( $\left.\mathrm{PGE}_{2}\right)$, nitric oxide (NO), hemeoxigenase-1 and indoleamine-2,3dioxygenase (IDO) $[136,137]$.

On the other hand, MSCs also inhibit the following: proliferation of monocytes and their differentiation into macrophages [138]; differentiation of monocytes and haematopoietic progenitors into mature dendritic cells $[139,140]$, and the de-differentiation of macrophages into monocytes [138]. In addition, MSCs induce dendritic cells to lose their ability to stimulate allo-responses and acquire a regulatory phenotype due to the production of large amounts of IL-10 [133]. Similarly, MSC-derived PGE $_{2}$ alters the cytokine secretion profile of dendritic cells and MSCs alter natural killer (NK) cell phenotype as well as suppress NK proliferation and cytokine secretion [141] through the production of soluble factors such as TGF- $\beta 1$ and PGE,

MSC anti-inflammatory effect is mediated by cytokines such as TGF- $\beta 1$ [142], IL-10, IL-12p70, IL-17E, IL-27 IL-13 [142,143], IL-1 receptor antagonist (IL1RA), IL-18 binding protein (IL-18BP), ciliary neurotrophic factor (CNTF), neurotrophin 3 (NT-3) factors [142,143], among others. On the other hand, MSC acellular derivatives have also been found to contain pro-inflammatory cytokines, such as IL1b [142], IL-6 [144,145], IL-8 [146,147] and IL-9 [147], that are in balance with the anti-inflammatory cytokines, and this balance may determine the ultimate response in the tissue. Nevertheless, it is also remarkable that MSC acellular derivatives inhibit pro-inflammatory cytokines (for example, interferon (IFN) and TNFa), while increasing anti-inflammatory IL-10 release [143,148]. Specifically, Legaki et al. reported that MSC acellular derivatives significantly reduced the mRNA expression of IL-6, IL-8, TNFa and macrophage inflammatory proteins 1 (MIP-1), and increased the mRNA expression of the IL-10 anti-inflammatory cytokine [149]

A number of these pro-inflammatory factors are involved in the acute inflammation period, a crucial phase in the wound healing process that leads to structural and functional repair of the injured tissue. Particularly, the inflammatory mediators that are released at the wound site and significantly contribute to the wound healing process are TGF- $\beta 1$, IL- 6 , and IL-8. In a similar way, IL-6 plays a major role in both the balancing of the pro-inflammatory/anti-inflammatory pathways, and the stress response.

Stimulation of angiogenesis: Because of the fact that MSC acellular derivatives have shown to play a more relevant role in angiogenesis than MSCs, therapeutic approaches are currently developed using only the bioactive factors produced by MSCs $[25,150,151]$.

MSC acellular derivatives can trigger vessel regeneration in ulcers by different mechanisms, mainly through vasculogenesis (the novo blood vessel formation from endothelial precursors or angioblasts), angiogenesis (the sprouting of existing vessels or intussusceptive angiogenesis), and arteriogenesis (the growth of collateral vessels), which have been mostly associated with angiogenic factors that are present in the secretome of MSCs [152,153]. They have been shown to induce proliferation, migration, and tube formation of endothelial colony-forming cells [152]

MSC acellular derivatives induce EC migration and chemiotaxis through factors such as CXCL-12/16 [154], CCN3 [155], and HGF [156]. EC migration initiates vascular reconstruction and allows endothelial tip cells to become invasive and to form both filopodia and lammellipodia, in response to guidance cues. At the same time, stalk cells, which lie behind tip cells, proliferate, extend the vessels and form extracellular matrix, junctions and lumens [157]. During this angiogenic process, the MSC acellular derivatives support the entire neo-vascular niche as well as rise the proliferation, survival and maturation of the cells involved in this process [152]. Some of these essential acellular derivatives are Ang-2 [158], endothelin-1 [159], Upa [160], VEGF [161], PDGF-AA/BB [162], placental growth factor (PIGF) [163] and FGF-7 [164].

Despite the fact that MSC acellular derivatives induce angiogenesis, it is important to highlight that this secretome also contains antiangiogenic regulators, such as TIMP-1/4 [165], serpin F1 and Thrombospondin-1/2 [166], which may block the migration of ECs. In this context, MSC acellular derivatives may modulate the angiogenesis mechanism in the wound healing process through complex interactions that may occur between both their pro-angiogenic and anti-angiogenic regulators [152].

Stimulation of proliferation and migration of local keratinocytes and dermal fibroblasts: MSC acellular derivatives are being rigorously investigated as a means to accelerate the proliferation, migration and differentiation of keratinocytes and dermal fibroblasts, in order to regulate the complex interactions that occur during wound healing $[123,167,168]$. Scratch assays revealed that, relative to the control (medium with serum), dermal fibroblasts and keratinocytes enhanced their rate of wound closure when exposed to MSC acellular derivatives by increasing their migration instead of their proliferation rates [167] However, Seung et al. reported a significant increase in the proliferation rate of both keratinocytes and dermal fibroblasts when exposed to MSC acellular derivatives obtained from AD-MSCs [169]. These discrepancies may have arisen because of differences in the MSC sources and the concentration of the MSC acellular derivatives employed in 
the studies. In fact, these derivatives appeared to influence dermal fibroblast migration rate in a dose-dependent manner [170]. Indeed, by increasing MSC concentration (by $40 \%$ or more), the migration rate of fibroblasts significantly decreased [170]. These results might suggest that the production of chemoattractant cytokines by MSCs varies depending on their confluency, creating a distinct microenvironment and secreting variable amounts of the attractant molecules.

To gain insight into the role of MSC acellular derivatives on wound healing progression, some researchers have compared the effect of MSC and fibroblast acellular derivatives on keratinocyte function and behavior, since dermal fibroblasts are known to be essential in the skin regeneration process. Specifically, Liwen et al. mimicked the normal wound healing environment by growing BM-MSCs and fibroblasts under hypoxic conditions and collected their acellular derivatives. Proliferation and migration assays performed on keratinocytes and ECs demonstrated that MSC acellular derivatives had a greater mitogenic and chemoattractive effect than fibroblast acellular derivatives. Indeed, MSC acellular derivatives analysis confirmed that MSCs expressed higher levels of KGF-1, PDGF, EGF, IGF-1 compared to dermal fibroblasts [122,171]. In addition, data from in vivo studies showed an accelerated wound closure when MSC acellular derivatives were used [122,171]. Similarly, AD-MSCs and fibroblasts have been used as a support for keratinocyte growth in two-dimensional (2D) and three-dimensional (3D) contexts, in order to better understand the paracrine factors secreted by these two cell types that are involved in the improvement of cutaneous wound healing [171]. By growing keratinocytes in MSC acellular derivatives, the number of cells in the transition from $\mathrm{G}_{2}$ phase to mitosis significantly increased compared to cells grown in fibroblast acellular derivatives, which sustained the cells on $\mathrm{G}_{0} / \mathrm{G}_{1}$ phases. However, in $3 \mathrm{D}$ contexts, AD-MSC acellular derivatives stimulated the abnormal keratinocyte expression of cytokeratins 5, 14 and 19, suggesting the induction of unusual hyperproliferation [169]. That said, future studies would need to incorporate a higher number of 3D-biomimetic culture systems to obtain more physiologically appropriate results.

On the other hand, during normal wound healing, keratinocyte migration is accelerated by EGF and TGF- $\beta$ [172], while keratinocyte proliferation is induced by EGF, bFGF, keratinocyte growth factor-1 (KGF-1) and IGF-1 [172,173]. Likewise, PDGF, TGF- $\beta$, connective tissue growth factor (CTGF) and nerve growth factors act as chemoattractants for dermal fibroblasts, while their proliferation is influenced by the presence of EGF, FGF, PDGF, TGF- $\beta$, CTGF and IGF1 [174]. Collectively, the MSC acellular derivative effect over dermal fibroblasts and keratinocytes merit further investigation as "off-theshelf" therapeutic options to promote healing of chronic ulcers.

ECM remodeling: ECM plays a number of critical roles in the wound healing process, which include supplying information and signals to the surrounding cells, as well as providing structural support [175]. In this context, MSC acellular derivatives can modulate the ECM healing microenvironment by remodeling the matrix and promoting its biosynthesis, stimulating different biological activities at the tissue or cellular levels $[150,175]$.

In fact, Arango et al. conducted a study to elucidate the role of MSC acellular derivatives on wound healing using different animal models, in particular, a diabetic mouse model. The results revealed that the wounds treated with the derivatives improved the synthesis, deposition and organization of collagen fibers at the dermal matrix, relative to the wounds treated with MSCs only $[124,176]$. Another recent study showed that the intravenous injection of acellular derivatives promoted cutaneous wound repair when exosomes secreted by human AD-MSCs (AD-Exos) were administered in murine incisional wounds. Wang et al. observed an improved wound healing process in vivo, which was mediated by the following mechanisms: i) increase in the ratio of collagen III to collagen I, ii) prevention of fibroblast differentiation into myofibroblasts, and iii) increase in the ratio of TGF- $\beta 3$ to TGF- $\beta 1$. In addition, AD-Exos enhanced the matrix metalloproteinase-3 (MMP3) expression of skin dermal fibroblasts by activating the ERK/MAPK pathway, leading to a high ratio of MMP3 to tissue inhibitor of matrix metalloproteinase-1 (TIMP-1), which was also beneficial for ECM remodeling [177]. That said, MMP production is inhibited by TIMPs, some of which are found in the MSC acellular derivatives, such as TIMP-1 and TIMP-4 [152]. Also, MMPs have been shown to regulate the cell-cell and cell-matrix signaling through the release of cytokines and growth factors sequestered in the ECM, as well as the exhibition of bioactive domains in the components of the ECM. Similarly, MMPs modify cell surface receptors and junctional proteins, regulating signaling processes in the cell in the wound healing microenvironment, which include: migration, proliferation, differentiation, mobility and cell death, thus, playing a pleiotropic role in the wound healing process $[178,179]$. Consequently, the degradation of the matrix allows to activate the cells in the wound microenvironment, which can initiate an indirect remodeling process.

There are important components of MSC acellular derivatives that produce an anti-fibrotic effect, which significantly allows the attenuation of scar formation during wound healing by ECM remodeling, being the most prominent factors HGF and IL-10 [180]. Fibroblasts respond to HGF by down-regulating their expression of TGF- $\beta 1$ and collagen type I/III [181]. In addition, HGF not also stimulates the up-regulation of MMP-1/3/13 expression in fibroblasts, promoting ECM turnover, but also increases the keratinocyte migration and proliferation as well as their expression of VEGF-A [182]. Therefore, HGF contributes to the generation of a high-quality and well-vascularized granulation tissue, while enhancing re-epithelialization of the wound [182].

Similarly, IL10 is able to reprogram wound fibroblasts to favor ECM remodeling by up-regulating the expression of MMPs and downregulating the expression of collagens [183], as well as attenuating the expression of pro-inflammatory cytokines in the wound, such as IL-6 and IL-8 [184]. Furthermore, IL-10 inhibits neutrophil invasion into the wound and prevents oxidative tissue damage [185]. As a result, expression of IL-10 contributes to both a resolution of the inflammatory stage and acceleration of the wound into the proliferation stage $[184,186]$

Antimicrobial effect: One of the most common complications of chronic skin wounds is the presence of opportunistic pathogens that colonize the skin ulcer, which constitutes one of the main reasons why chronic wounds do not heal in a short time [187]. Up-to-date literature shows conflicting data regarding the influence of MSCs on wound infection. Reported evidence suggests that MSCs may have pro- as well as anti-microbial effects, $[188,189]$ which seem to depend on MSC isolation and expansion conditions, cell source, doses, administration route, timing and wound microenvironment.

Several studies have shown that MSCs may provide an antimicrobial effect. Both un-stimulated and IFN- $\gamma$ stimulated human MSCs can inhibit the growth of Gram-negative bacteria, such as Escherichia coli and Pseudomonas aeruginosa, as well as the growth of Gram-positive pathogens, such as Staphylococcus aureus, Staphylococcus epidermidis, group B Streptococci and Enterococcus faecium [190,191]. Recent data has also shown that MSCs exerted a strong antimicrobial effect on 
preclinical models of polymicrobial sepsis [130,188,192,193], acute respiratory distress syndrome [194,195], cystic fibrosis infection $[130,196,197]$, and endotoxemic rat models (involving intravenous LPS injection) [198]. Indeed, the results suggest that MSCs are responsible for inhibiting and clearing bacterial growth, decreasing subject mortality, as well as reducing systemic inflammation and decreasing inflammatory cytokine levels.

MSC antimicrobial activity has also been proven in a clinical study aimed at treating patients suffering from acute respiratory distress syndrome (NCT01902082). Specifically, one intravenous dose of $1 \times 10^{6}$ cells/kg allogeneic AD-MSCs acted as a safe and feasible therapeutic tool for this infection [199], through the secretion of antimicrobial peptides such as: cathelicidin LL-37 [191,196,197], defensins [200], hepcidin [201], and lipocalin 2 [202], which prevented bacterial growth or killed the pathogens. The secretion of these soluble peptides improved resident phagocyte ability to clear bacteria by the up-regulation of pathways associated with monocyte/macrophage, phagocytosis, NK cell activity and antigen presentation [188]. Likewise, MSC antifungal activity has been associated with an increased amount of TH17 cells in the blood, promoting TH1-type immune responses and restraining the TH2-type ones [29,203]. Cumulatively, MSC acellular derivatives might become an innovative therapeutic tool for preventing and treating infected skin wounds by improving the conditions of the chronic cutaneous wound healing process $[130,187,204]$.

\section{Future Perspective}

The fascinating regenerative therapeutic effects of MSCs in a number of life-threatening human diseases have led them to become the most common and effective cell source in cell-based treatments. Nevertheless, some issues still require to be addressed in order to propose optimized therapeutic strategies, for instance: which route is more suited for the administration of MSCs? Which would be the most suitable biomaterials used for optimizing stem cells' transplant effectiveness? How does the local environment affect delivered MSC performance and action? Which is the best alternative culture protocol for the in vitro MSC expansion using xeno-free media before transplant? Which is the best source of donor cells for the degenerative disease under investigation?

On the other hand, several investigators have recently explored the possibility of replacing MSCs by their acellular derivatives for therapeutic applications since MSCs exert many of their effects via paracrine signaling. In fact, acellular derivatives could be a more promising therapeutic tool due to both their good manufacturing practice production and their release is less complex compared to living cells, resulting in reduced costs. In addition, the acellular derivatives could circumvent the current limitations associated with poor cell survival upon transplantation as well as provide the possibility to apply one or combined trophic factors as oriented therapies for diseases. Although it is undisputable that MSC therapy contributes to restoration of structural integrity and functionality of damaged tissue, resulting in functional advantage over other conventional strategies, these series of gaps still need to be addressed so that these potential therapeutic tools could have transition from bench to bedside and become more feasible in the near future.

\section{Acknowledgements}

The authors would like to thank Dr. Viviana Guiza-Arguello for English editing of the paper.

\section{Funding}

This work was supported by a grant from Colciencias (Code 651777757697).

\section{References}

1. Raffetto JD (2016) Pathophysiology of wound healing and alterations in venous leg ulcers-review. Phlebology 31: 56-62. [PubMed]

2. Park JW (2017) Advanced Growth Factor Delivery Systems in Wound Management and Skin Regeneration. Molecules.

3. Reinke JM (2012) Wound repair and regeneration. Eur Surg Res 49: 35-43. [PubMed]

4. Fonder MA (2008) Treating the chronic wound: A practical approach to the care of nonhealing wounds and wound care dressings. J Am Acad Dermatol 58 185-206.

5. Zhao R (2016) Inflammation in Chronic Wounds. Int J Mol Sci 17: 10. [PubMed]

6. Lindholm C (2016) Wound management for the 21st century: combining effectiveness and efficiency. Int Wound J 2: 5-15.

7. Sen CK (2009) Human skin wounds: a major and snowballing threat to public health and the economy. Wound Repair Regen 17: 763-771. [PubMed]

8. Han G (2017) Chronic Wound Healing: A Review of Current Management and Treatments. Adv Ther 34: 599-610.

9. Pop MA (2017) Biomaterials: A potential pathway to healing chronic wounds? Exp Dermatol 26: 760-763. [PubMed]

10. Kim KH (2017) Mesenchymal stromal cells: properties and role in management of cutaneous diseases. J Eur Acad Dermatol Venereol 31: 414-423.

11. Friedenstein AJ (1968) Heterotopic of bone marrow. Analysis of precursor cells for osteogenic and hematopoietic tissues. Transplantation 6: 230-247. [PubMed]

12. Friedenstein AJ (1974) Precursors for fibroblasts in different populations of hematopoietic cells as detected by the in vitro colony assay method. Exp Hematol 2: 83-92.

13. Friedenstein AJ (1970) The development of fibroblast colonies in monolaye cultures of guinea-pig bone marrow and spleen cells. Cell Tissue Kinet 3: 393403. [PubMed]

14. Friedenstein AJ (1966) Osteogenesis in transplants of bone marrow cells. J Embryol Exp Morphol 16: 381-390.

15. Friedenstein AJ (1980) Stromal mechanisms of bone marrow: cloning in vitro and retransplantation in vivo. Haematol Blood Transfus 25: 19-29. [PubMed]

16. Hass $R$ (2011) Different populations and sources of human mesenchymal stem cells (MSC): A comparison of adult and neonatal tissue-derived MSC. Cell Commun Signal 9: 12.

17. Nancarrow-Lei R (2017) A Systemic Review of the Sources of Adult Mesenchymal Stem Cells and their Suitability in Musculoskeletal Applications. Curr Stem Cell Res Ther 7: 10. [PubMed]

18. Schneider S (2017) Adipose-derived mesenchymal stem cells from liposuction and resected fat are feasible sources for regenerative medicine. Eur $\mathrm{J}$ Med Res 22: 17.

19. Frese L (2016) Adipose Tissue-Derived Stem Cells in Regenerative Medicine Transfus Med Hemother 43: 268-274. [PubMed]

20. Strioga M (2012) Same or not the same? Comparison of adipose tissue-derived versus bone marrow-derived mesenchymal stem and stromal cells. Stem Cells Dev 21: 2724-2752.

21. Karaoz E (2017) Comparative Analyses of Immunosuppressive Characteristics of Bone-Marrow. Wharton's Jelly. and Adipose Tissue-Derived Human Mesenchymal Stem Cells. Turk J Haematol 34: 213-225. [PubMed]

22. Ribeiro A (2013) Mesenchymal stem cells from umbilical cord matrix. adipose tissue and bone marrow exhibit different capability to suppress peripheral blood B. natural killer and T cells. Stem Cell Res Ther 4: 125

23. $\mathrm{Xu} \mathrm{L} \mathrm{(2017)} \mathrm{Tissue} \mathrm{source} \mathrm{determines} \mathrm{the} \mathrm{differentiation} \mathrm{potentials} \mathrm{of}$ mesenchymal stem cells: a comparative study of human mesenchymal stem cells from bone marrow and adipose tissue. Stem Cell Res Ther 8: 275 [PubMed]

24. Mansilla E (2015) Cadaveric bone marrow mesenchymal stem cells: first experience treating a patient with large severe burns. Burns Trauma 3: 17 
25. Vizoso FJ (2017) Mesenchymal Stem Cell Secretome: Toward Cell-Free Therapeutic Strategies in Regenerative Medicine. Int J Mol Sci 18: 1. [PubMed]

26. Sotiropoulou PA (2006) Characterization of the optimal culture conditions for clinical scale production of human mesenchymal stem cells. Stem Cells 24 : $462-471$.

27. Smith JR (2004) Isolation of a highly clonogenic and multipotential subfraction of adult stem cells from bone marrow stroma. Stem Cells. 22: 823-831. [PubMed]

28. Raposio E (2017) Adipose-derived stem cells: Comparison between two methods of isolation for clinical applications. Ann Med Surg (Lond) 20: 87-91.

29. Abdelrazik H (2011) Mesenchymal stem cells expanded in human platelet lysate display a decreased inhibitory capacity on T- and NK-cell proliferation and function. Eur J Immunol 41: 3281-3290. [PubMed]

30. Abdi R (2008) Immunomodulation by mesenchymal stem cells: a potential therapeutic strategy for type 1 diabetes. Diabetes 57: 1759-1767.

31. Atashi F, Jaconi ME (2015) Pittet-Cuenod. A. Modarressi. Autologous plateletrich plasma: a biological supplement to enhance adipose-derived mesenchymal stem cell expansion. Tissue Eng Part C Methods. 21: 253-262. [PubMed]

32. Russell KA (2015) Canine Platelet Lysate Is Inferior to Fetal Bovine Serum for the Isolation and Propagation of Canine Adipose Tissue- and Bone MarrowDerived Mesenchymal Stromal Cells. PLoS One 10: e0136621.

33. Astori G (2016) Platelet lysate as a substitute for animal serum for the ex-vivo expansion of mesenchymal stem/stromal cells: present and future. Stem Cell Res Ther 7: 93. [PubMed]

34. Bieback K (2013) Platelet lysate as replacement for fetal bovine serum in mesenchymal stromal cell cultures. Transfus Med Hemother 40: 326-335. [PubMed]

35. Li F (2017) Function and Therapeutic Potential of Mesenchymal Stem Cells in Atherosclerosis. Front Cardiovasc Med 4: 32. [PubMed]

36. Schallmoser K (2008) Rapid large-scale expansion of functional mesenchymal stem cells from unmanipulated bone marrow without animal serum. Tissue Eng Part C Methods 14: 185-196.

37. Jin HJ (2013) Comparative analysis of human mesenchymal stem cells from bone marrow. adipose tissue. and umbilical cord blood as sources of cell therapy. Int J Mol Sci 14: 17986-18001. [PubMed]

38. Brown PT (2014) Characterization and evaluation of mesenchymal stem cells derived from human embryonic stem cells and bone marrow. Cell Tissue Res 358: 149-164.

39. Bader P (2018) Effective treatment of steroid and therapy-refractory acute graft-versus-host disease with a novel mesenchymal stromal cell product (MSC-FFM). Bone Marrow Trans 2: 10. [PubMed]

40. Kuci Z (2016) Mesenchymal stromal cells from pooled mononuclear cells of multiple bone marrow donors as rescue therapy in pediatric severe steroidrefractory graft-versus-host disease: a multicenter survey. Haematologica 101 985-994.

41. Dominici M (2006) Minimal criteria for defining multipotent mesenchymal stromal cells. The International Society for Cellular Therapy position statement. Cytotherapy 8: 315-317. [PubMed]

42. Le Blanc K (2003) HLA expression and immunologic properties of differentiated and undifferentiated mesenchymal stem cells. Exp Hematol 31: 890-896.

43. Mareschi K (2001) Isolation of human mesenchymal stem cells: bone marrow versus umbilical cord blood. Haematologica 86: 1099-1100. [PubMed]

44. Lam MT (2013) Effective delivery of stem cells using an extracellular matrix patch results in increased cell survival and proliferation and reduced scarring in skin wound healing. Tissue Eng Part A 19: 738-747.

45. Rustad KC (2012) Enhancement of mesenchymal stem cell angiogenic capacity and stemness by a biomimetic hydrogel scaffold. Biomaterials 33: $80-$ 90. [PubMed]

46. Nie C (2011) Locally administered adipose-derived stem cells accelerate wound healing through differentiation and vasculogenesis. Cell Transplant 20 : 205-216.

47. Pratheesh MD (2017) Evaluation of persistence and distribution of intra-dermally administered PKH26 labelled goat bone marrow derived mesenchymal stem cells in cutaneous wound healing model. Cytotech 69: 841-849. [PubMed]
48. Hanson SE (2016) Local delivery of allogeneic bone marrow and adipose tissue-derived mesenchymal stromal cells for cutaneous wound healing in a porcine model. J Tissue Eng Regen Med 10: E90-E100.

49. Ouma GO (2012) Targets and delivery methods for therapeutic angiogenesis in peripheral artery disease. Vasc Med 17: 174-192. [PubMed]

50. Shou K (2017) Enhancement of Bone-Marrow-Derived Mesenchymal Stem Cell Angiogenic Capacity by NPWT for a Combinatorial Therapy to Promote Wound Healing with Large Defect. Biomed Res Int 1: 7920265.

51. Conget P (2010) Replenishment of type VII collagen and re-epithelialization of chronically ulcerated skin after intradermal administration of allogeneic mesenchymal stromal cells in two patients with recessive dystrophic epidermolysis bullosa. Cytother 12: 429-431. [PubMed]

52. Dash NR (2009) Targeting nonhealing ulcers of lower extremity in human through autologous bone marrow-derived mesenchymal stem cells. Rejuvenation Res 12: 359-366.

53. Yoshikawa $T$ (2008) Wound therapy by marrow mesenchymal cel transplantation. Plast Reconstr Surg 121: 860-877. [PubMed]

54. Falanga V (2007) Autologous bone marrow-derived cultured mesenchymal stem cells delivered in a fibrin spray accelerate healing in murine and human cutaneous wounds. Tissue Eng 13: 1299-1312.

55. Wang Q (2015) Second-harmonic generation microscopy for assessment of mesenchymal stem cell-seeded acellular dermal matrix in wound-healing. Biomater 53: 659-668. [PubMed]

56. Formigli $L$ (2015) MSCs seeded on bioengineered scaffolds improve skin wound healing in rats. Wound Repair Regen 23: 115-123.

57. Huang SP (2012) Adipose-derived stem cells seeded on acellular dermal matrix grafts enhance wound healing in a murine model of a full-thickness defect. Ann Plast Surg. 69: 656-662. [PubMed]

58. Halliwell B (2004) Measuring reactive species and oxidative damage in vivo and in cell culture: how should you do it and what do the results mean? $\mathrm{Br} J$ Pharmacol 142: 231-255.

59. Chen MF (2006) The sensitivity of human mesenchymal stem cells to ionizing radiation. Int J Radiat Oncol Biol Phys 66: 244-253. [PubMed]

60. Chen SL (2004) Effect on left ventricular function of intracoronary transplantation of autologous bone marrow mesenchymal stem cell in patients with acute myocardial infarction. Am J Cardiol 94: 92-95.

61. Kurozumi K (2005) Mesenchymal stem cells that produce neurotrophic factors reduce ischemic damage in the rat middle cerebral artery occlusion model. Mol Ther 11: 96-104. [PubMed]

62. Lee RH (2006) Multipotent stromal cells from human marrow home to and promote repair of pancreatic islets and renal glomeruli in diabetic NOD/scid mice. Proc Natl Acad Sci USA 103: 17438-17443.

63. Valle-Prieto A (2010) Human mesenchymal stem cells efficiently manage oxidative stress. Stem Cells Dev 19: 1885-1893. [PubMed]

64. Salmon AB (2009) Richardson. Lack of methionine sulfoxide reductase A in mice increases sensitivity to oxidative stress but does not diminish life span. FASEB J 23: 3601-3608.

65. Silva WA (2003) The profile of gene expression of human marrow mesenchymal stem cells. Stem Cells 21: 661-669. [PubMed]

66. Pattappa G (2011) The metabolism of human mesenchymal stem cells during proliferation and differentiation. J Cell Physiol 226: 2562-2570.

67. Spencer JA (2014) Direct measurement of local oxygen concentration in the bone marrow of live animals. Nature 508: 269-273. [PubMed]

68. Palomaki D (2013) HIF-1alpha is upregulated in human mesenchymal stem cells. Stem Cells 31: 1902-1909.

69. Semenza GL (2011) Regulation of metabolism by hypoxia-inducible factor 1. Cold Spring Harb Symp Quant Biol 76: 347-353. [PubMed]

70. Forsythe JA (1996) Activation of vascular endothelial growth factor gene transcription by hypoxia-inducible factor 1 . Mol Cell Biol 16: 4604-4613.

71. Ivan M (2002) Biochemical purification and pharmacological inhibition of a mammalian prolyl hydroxylase acting on hypoxia-inducible factor. Proc Nat Acad Sci USA 99: 13459-13464. 
72. Liu Y (2015) Metabolic regulation of mesenchymal stem cell in expansion and therapeutic application. Biotechnol Prog 31: 468-481. [PubMed]

73. Heywood HK (2008) Monolayer expansion induces an oxidative metabolism and ROS in chondrocytes. Biochem Biophys Res Commun 373: 224-229.

74. Wang DW (2005) Influence of oxygen on the proliferation and metabolism of adipose derived adult stem cells. J Cell Physiol 204: 184-191. [PubMed]

75. Chen CT (2008) Coordinated changes of mitochondrial biogenesis and antioxidant enzymes during osteogenic differentiation of human mesenchymal stem cells. Stem Cells 26: 960-968.

76. Chen CT (2012) Mitochondrial bioenergetic function and metabolic plasticity in stem cell differentiation and cellular reprogramming. Biochim Biophys Acta 1820: 571-576. [PubMed]

77. Tormos KV (2011) Mitochondrial complex III ROS regulate adipocyte differentiation. Cell Metab 14: 537-544.

78. Tsai CC (2011) Hypoxia inhibits senescence and maintains mesenchymal stem cell properties through down-regulation of E2A-p21 by HIF-TWIST. Blood 117: 459-469. [PubMed]

79. Wang M (2006) Human progenitor cells from bone marrow or adipose tissue produce VEGF. HGF. and IGF-I in response to TNF by a p38 MAPK-dependent mechanism. Am J Physiol Regul Integr Comp Physiol 291: R880-884.

80. Deschepper M (2013) Proangiogenic and prosurvival functions of glucose in human mesenchymal stem cells upon transplantation. Stem Cells 31: 526-535. [PubMed]

81. Kuo TK (2008) Stem cell therapy for liver disease: parameters governing the success of using bone marrow mesenchymal stem cells. Gastroenter 134: 2111-2121

82. Lanza C (2009) Neuroprotective mesenchymal stem cells are endowed with a potent antioxidant effect in vivo. J Neurochem 110: 1674-1684. [PubMed]

83. Vojtassak J (2006) Autologous biograft and mesenchymal stem cells in treatment of the diabetic foot. Neuro Endocrinol Lett 27: 134-137.

84. Lu H (2016) Erythropoietin-activated mesenchymal stem cells promote healing ulcers by improving microenvironment. J Surg Res 205: 464-473. [PubMed]

85. Stolzing A (2006) Glucose-induced replicative senescence in mesenchymal stem cells. Rejuvenation Res 9: 31-35

86. Strong AL (2017) Stem Cells and Tissue Engineering: Regeneration of the Skin and Its Contents. Clin Plast Surg 44: 635-650. [PubMed]

87. Squillaro T (2016) Clinical Trials With Mesenchymal Stem Cells: An Update. Cell Transplant 25: 829-848.

88. Huselstein C (2017) Mechanobiology of mesenchymal stem cells: Which interest for cell-based treatment? Biomed Mater Eng 28: S47-S56. [PubMed]

89. Spees JL (2016) Mechanisms of mesenchymal stem/stromal cell function. Stem Cell Res Ther 7: 125

90. Rustad KC (2012) Mesenchymal Stem Cells Home to Sites of Injury and Inflammation. Adv Wound Care (New Rochelle) 1: 147-152. [PubMed]

91. Wei X (2013) Mesenchymal stem cells: a new trend for cell therapy. Acta Pharmacol Sin 34: 747-754

92. Gnecchi M (2016) Paracrine Mechanisms of Mesenchymal Stem Cells in Tissue Repair. Methods Mol Biol 1416: 123-146. [PubMed]

93. Caplan Al (2011) The MSC: an injury drugstore. Cell Stem Cell 9: 11-15.

94. Phinney DG (2015) Mesenchymal stem cells use extracellular vesicles to outsource mitophagy and shuttle microRNAs. Nat Commun 6: 8472. [PubMed]

95. Onfelt B (2006) Structurally distinct membrane nanotubes between human macrophages support long-distance vesicular traffic or surfing of bacteria. $J$ Immunol 177: 8476-8483.

96. Spees JL (2006) Mitochondrial transfer between cells can rescue aerobic respiration. Proc Natl Acad Sci USA 103: 1283-1288. [PubMed]

97. Roy S (2015) Paracrine signaling mediated at cell-cell contacts. Bioessays 37 25-33.

98. Gustafson T (1961) Studies on the cellular basis of morphogenesis in the sea urchin embryo. Gastrulation in vegetalized larvae. Exp Cell Res 22: 437-449.
99. Plotnikov EY (2008) Cell-to-cell cross-talk between mesenchymal stem cells and cardiomyocytes in co-culture. J Cell Mol Med 12: 1622-1631. [PubMed]

100.Liu K (2014) Mesenchymal stem cells rescue injured endothelial cells in an in vitro ischemia-reperfusion model via tunneling nanotube like structuremediated mitochondrial transfer. Microvasc Res 92: 10-18. [PubMed]

101.Li X (2014) Mitochondrial transfer of induced pluripotent stem cell-derived mesenchymal stem cells to airway epithelial cells attenuates cigarette smokeinduced damage. Am J Respir Cell Mol Biol 51: 455-465. [PubMed]

102. Jiang D (2016) Mitochondrial transfer of mesenchymal stem cells effectively protects corneal epithelial cells from mitochondrial damage. Cell Death Dis $7:$ e2467. [PubMed]

103. Bura A (2014) Phase I trial: the use of autologous cultured adipose-derived stroma/stem cells to treat patients with non-revascularizable critical limb ischemia. Cytotherapy 16: 245-257.

104. Bey E (2010) Emerging therapy for improving wound repair of severe radiation burns using local bone marrow-derived stem cell administrations. Wound Repair Regen 18: 50-58. [PubMed]

105. Kim SW (2012) Amniotic mesenchymal stem cells enhance wound healing in diabetic NOD/SCID mice through high angiogenic and engraftment capabilities. PLoS One 7: e41105. [PubMed]

106. Kong P (2013) Placenta mesenchymal stem cell accelerates wound healing by enhancing angiogenesis in diabetic Goto-Kakizaki (GK) rats. Biochem Biophys Res Commun 438: 410-419.

107. Kuo YR (2011) Bone marrow-derived mesenchymal stem cells enhanced diabetic wound healing through recruitment of tissue regeneration in a rat model of streptozotocin-induced diabetes. Plast Reconstr Surg 128: 872-880. [PubMed]

108. Shrestha C (2013) Enhanced healing of diabetic wounds by subcutaneous administration of human umbilical cord derived stem cells and their conditioned media. Int J Endocrinol 10: 592454.

109. Ma D (2015) In vitro characterization of human hair follicle dermal sheath mesenchymal stromal cells and their potential in enhancing diabetic wound healing. Cytotherapy 17: 1036-1051. [PubMed]

110. Sasaki M (2008) Mesenchymal stem cells are recruited into wounded skin and contribute to wound repair by transdifferentiation into multiple skin cell type. $J$ Immunol 180: 2581-2587. [PubMed]

111. Li TD (2008) Myocardial repair achieved by the intramyocardial implantation of adult cardiomyocytes in combination with bone marrow cells. Cell Transplant 17: 695-703. [PubMed]

112. Toma C (2009) Fate of culture-expanded mesenchymal stem cells in the microvasculature: in vivo observations of cell kinetics. Circ Res 104: 398-402. [PubMed]

113. Lee RH (2009) Intravenous hMSCs improve myocardial infarction in mice because cells embolized in lung are activated to secrete the anti-inflammatory protein TSG-6. Cell Stem Cell 5: 54-63.

114. Eggenhofer E (2012) Mesenchymal stem cells are short-lived and do not migrate beyond the lungs after intravenous infusion. Front Immunol 3: 297. [PubMed]

115. Chen L (2014) Conditioned medium from hypoxic bone marrow-derived mesenchymal stem cells enhances wound healing in mice. PLoS One 9: e96161. [PubMed]

116. Maguire G (2013) Stem cell therapy without the cells. Commun Integr Biol 6:) e26631.

117. Luo G (2010) Promotion of cutaneous wound healing by local application of mesenchymal stem cells derived from human umbilical cord blood. Wound Repair Regen 18: 506-513. [PubMed]

118. Wu Y (2007) Mesenchymal stem cells enhance wound healing through differentiation and angiogenesis. Stem Cells 25: 2648-2659. [PubMed]

119. Hu C (2013) CXCL12/CXCR4 axis promotes mesenchymal stem cell mobilization to burn wounds and contributes to wound repair. J Surg Res 183 427-434. [PubMed]

120. Maharlooei MK (2011) Adipose tissue derived mesenchymal stem cell (ADMSC) promotes skin wound healing in diabetic rats. Diabetes Res Clin Pract 93: 228-234. [PubMed] 
121. Wu Y (2014) Bone marrow-derived mesenchymal stem cell attenuates skin fibrosis development in mice. Int Wound J 11: 701-710. [PubMed]

122. Chen L (2008) Paracrine factors of mesenchymal stem cells recruit macrophages and endothelial lineage cells and enhance wound healing. PLoS One 3: e1886. [PubMed]

123. Kim MH (2017) Conditioned medium from the three-dimensional culture of human umbilical cord perivascular cells accelerate the migration and proliferation of human keratinocyte and fibroblast. J Biomater Sci Polym Ed 10: 1-15. [PubMed]

124.de Mayo T (2017) The role of bone marrow mesenchymal stromal cell derivatives in skin wound healing in diabetic mice. PLoS One 12: e0177533. [PubMed]

125. Beer L (2017) Cell secretome based drug substances in regenerative medicine: when regulatory affairs meet basic science. Ann Transl Med 5: 170.

126. Stoff A (2009) Promotion of incisional wound repair by human mesenchymal stem cell transplantation. Exp Dermatol 18: 362-369. [PubMed]

127.Gardien KL (2014) Progress towards cell-based burn wound treatments. Regen Med 9: 201-218.

128. Liu L (2014) Human umbilical cord mesenchymal stem cells transplantation promotes cutaneous wound healing of severe burned rats. PLoS One 9: e88348. [PubMed]

129. Khosrotehrani K (2013) Mesenchymal stem cell therapy in skin: why and what for?. Exp Dermatol 22: 307-310. [PubMed]

130. Alcayaga-Miranda F (2017) Antimicrobial Activity of Mesenchymal Stem Cells: Current Status and New Perspectives of Antimicrobial Peptide-Based Therapies. Front Immunol 8: 339.

131. Ryan JM (2005) Mesenchymal stem cells avoid allogeneic rejection. J Inflamm (Lond) 2: 8.

132. Fierabracci S (2016) The Use of Mesenchymal Stem Cells for the Treatment of Autoimmunity: From Animals Models to Human Disease. Curr Drug Targets 17: 229-238. [PubMed]

133. Aggarwal S (2005) Human mesenchymal stem cells modulate allogeneic immune cell responses. Blood 105: 1815-1822. [PubMed]

134.Shi M (2011) Immunomodulatory properties and therapeutic application of mesenchymal stem cells. Clin Exp Immunol 164: 1-8. [PubMed]

135.Liang X (2014) Paracrine mechanisms of mesenchymal stem cell-based therapy: current status and perspectives. Cell Transplant 23: 1045-1059. [PubMed]

136. Chabannes D (2007) A role for heme oxygenase-1 in the immunosuppressive effect of adult rat and human mesenchymal stem cells. Blood 110: 3691-3694. [PubMed]

137. Gieseke F (2007) Human multipotent mesenchymal stromal cells inhibit proliferation of PBMCs independently of IFNgammaR1 signaling and IDO expression. Blood 110: 2197-2200

138. De Coppi P (2007) Isolation of amniotic stem cell lines with potential for therapy. Nat Biotechnol 25: 100-106. [PubMed]

139. Nauta AJ (2006) Mesenchymal stem cells inhibit generation and function of both CD34+-derived and monocyte-derived dendritic cells. J Immunol 177: 2080-2087.

140. Ramasamy R (2007) Mesenchymal stem cells inhibit dendritic cell differentiation and function by preventing entry into the cell cycle. Transplantation. 83: 71-76. [PubMed]

141. Sotiropoulou PA (2006) Interactions between human mesenchymal stem cells and natural killer cells. Stem Cells 24: 74-85. [PubMed]

142.Zagoura DS (2012) Therapeutic potential of a distinct population of human amniotic fluid mesenchymal stem cells and their secreted molecules in mice with acute hepatic failure. Gut 61: 894-906. [PubMed]

143. Bermudez MA (2016) Anti-inflammatory effect of conditioned medium from human uterine cervical stem cells in uveitis. Exp Eye Res 149: 84-92.

144. Cantinieaux D (2013) Conditioned medium from bone marrow-derived mesenchymal stem cells improves recovery after spinal cord injury in rats: an original strategy to avoid cell transplantation. PLoS One 8: e69515. [PubMed]
145. See F (2011) Therapeutic effects of human STRO-3-selected mesenchyma precursor cells and their soluble factors in experimental myocardial ischemia. J Cell Mol Med 15: 2117-2129. [PubMed]

146. Mirabella T (2011) Amniotic liquid derived stem cells as reservoir of secreted angiogenic factors capable of stimulating neo-arteriogenesis in an ischemic model. Biomaterials 32: 3689-3699. [PubMed]

147. Lee MJ (2011) Enhancement of wound healing by secretory factors of endothelial precursor cells derived from human embryonic stem cells. Cytotherapy 13: 165-178. [PubMed]

148. Yi T (2012) Immunomodulatory properties of mesenchymal stem cells and their therapeutic applications. Arch Pharm Res 35: 213-221. [PubMed]

149. Legaki E (2016) Therapeutic Potential of Secreted Molecules Derived from Human Amniotic Fluid Mesenchymal Stem/Stroma Cells in a Mice Model of Colitis. Stem Cell Rev 12: 604-612. [PubMed]

150. Motegi SI (2017) Mesenchymal stem cells: The roles and functions in cutaneous wound healing and tumor growth. J Dermatol Sci 86: 83-89. [PubMed]

151. Cao Y (2017) Mesenchymal Stem Cells Improve Healing of Diabetic Foot Ulcer. J Diabetes Res 10: 9328347. [PubMed]

152. Watt SM (2013) The angiogenic properties of mesenchymal stem/stromal cells and their therapeutic potential. Br Med Bull 108: 25-53. [PubMed]

153. Kinnaird T (2004) Local delivery of marrow-derived stromal cells augments collateral perfusion through paracrine mechanisms. Circulation 109: 15431549. [PubMed]

154. Isozaki T (2013) Evidence that CXCL16 is a potent mediator of angiogenesis and is involved in endothelial progenitor cell chemotaxis : studies in mice with K/BxN serum-induced arthritis. Arthritis Rheum 65: 1736-1746. [PubMed]

155. Lin CG (2005) Integrin-dependent functions of the angiogenic inducer NOV (CCN3): implication in wound healing. J Biol Chem 280: 8229-8237. [PubMed]

156. Morishita $R$ (2004) Therapeutic angiogenesis using hepatocyte growth factor (HGF). Curr Gene Ther 4: 199-206. [PubMed]

157.Carmeliet P (2011) Molecular mechanisms and clinical applications of angiogenesis. Nature 473: 298-307. [PubMed]

158. Fagiani E (2013) Angiopoietins in angiogenesis. Cancer Lett 328: 18-26.

159. Salani G (2000) Endothelin-1 induces an angiogenic phenotype in cultured endothelial cells and stimulates neovascularization in vivo. Am J Pathol 157: 1703-1711. [PubMed]

160. Montuori N (2014) Role of uPA/uPAR in the modulation of angiogenesis. Chem Immunol Allergy 99: 105-122. [PubMed]

161. Hofer HR (2016) Secreted trophic factors of mesenchymal stem cells support neurovascular and musculoskeletal therapies. Stem Cell Res Ther 7: 131 [PubMed]

162. Battegay EJ (1994) PDGF-BB modulates endothelial proliferation and angiogenesis in vitro via PDGF beta-receptors. J Cell Biol 125: 917-928. [PubMed]

163. Nagy JA (2003) VEGF-A(164/165) and PIGF: roles in angiogenesis and arteriogenesis. Trends Cardiovasc Med 13: 169-175. [PubMed]

164. Gillis $P$ (1999) Bouck. Keratinocyte growth factor induces angiogenesis and protects endothelial barrier function. J Cell Sci 112: 2049-2057. [PubMed]

165. Reed MJ (2003) Inhibition of TIMP1 enhances angiogenesis in vivo and cell migration in vitro. Microvasc Res 65: 9-17. [PubMed]

166. Lawler PR (2012) Molecular basis for the regulation of angiogenesis by thrombospondin-1 and -2. Cold Spring Harb Perspect Med 2: a006627. [PubMed]

167. Walter MN (2010) Mesenchymal stem cell-conditioned medium accelerates skin wound healing: an in vitro study of fibroblast and keratinocyte scratch assays. Exp Cell Res 316: 1271-1281. [PubMed]

168. Ong HT (2017) Paracrine Activity from Adipose-Derived Stem Cells on In Vitro Wound Healing in Human Tympanic Membrane Keratinocytes. Stem Cells Dev 26: 405-418. [PubMed]

169. Lee SH (2012) Paracrine effects of adipose-derived stem cells on keratinocytes and dermal fibroblasts. Ann Dermatol 10: 136-143. [PubMed] 
170. Rodriguez-Menocal L (2012) Stimulation of skin and wound fibroblast migration by mesenchymal stem cells derived from normal donors and chronic wound patients. Stem Cells Transl Med 1: 221-229.

171. Alexaki VI (2012) Adipose tissue-derived mesenchymal cells support skin reepithelialization through secretion of KGF-1 and PDGF-BB: comparison with dermal fibroblasts. Cell Transplant 21: 2441-2454. [PubMed]

172. Bhora FY (1995) Effect of growth factors on cell proliferation and epithelialization in human skin. J Surg Res 59: 236-244. [PubMed]

173. Ishimoto S (2002) Direct application of keratinocyte growth factor. basic fibroblast growth factor and transforming growth factor-alpha during healing of tympanic membrane perforation in glucocorticoid-treated rats. Acta Otolaryngol 122: 468-473. [PubMed]

174. Werner S (2003) Regulation of wound healing by growth factors and cytokines. Physiol Rev 83: 835-870. [PubMed]

175. Rhodes JM (2007) The extracellular matrix and blood vessel formation: not just a scaffold. J Cell Mol Med 11: 176-205. [PubMed]

176. Bruna F (2016) Regenerative Potential of Mesenchymal Stromal Cells: AgeRelated Changes. Stem Cells Int 20: 1461648. [PubMed]

177. Wang L (2017) Exosomes secreted by human adipose mesenchymal stem cells promote scarless cutaneous repair by regulating extracellular matrix remodelling. Sci Rep 7: 13321. [PubMed]

178. Caley MP (2015) Metalloproteinases and Wound Healing. Adv Wound Care (New Rochelle) 4: 225-234. [PubMed]

179. Hyldig K (2017) Implications of Extracellular Matrix Production by Adipose Tissue-Derived Stem Cells for Development of Wound Healing Therapies. Int J Mol Sci 18: 10. [PubMed]

180. Jackson WM (2012) Mesenchymal stem cell therapy for attenuation of scar formation during wound healing. Stem Cell Res Ther 3: 20. [PubMed]

181. Mou S (2009) Hepatocyte growth factor suppresses transforming growth factor-beta-1 and type III collagen in human primary renal fibroblasts. Kaohsiung J Med Sci 25: 577-587. [PubMed]

182. Bevan E (2004) Diverse and potent activities of HGF/SF in skin wound repair. J Pathol 203: 831-838.

183. Reitamo S (1994) Interleukin-10 modulates type I collagen and matrix metalloprotease gene expression in cultured human skin fibroblasts. J Clin Invest 94: 2489-2492. [PubMed]

184. Liechty KW (2000) Fetal wound repair results in scar formation in interleukin10 -deficient mice in a syngeneic murine model of scarless fetal wound repair. J Pediatr Surg 35: 866-872. [PubMed]

185. Sato $Y$ (1999) Regulatory role of endogenous interleukin-10 in cutaneous inflammatory response of murine wound healing. Biochem Biophys Res Commun. 265: 194-199. [PubMed]

186. Peranteau WH (2008) IL-10 overexpression decreases inflammatory mediators and promotes regenerative healing in an adult model of sca formation. J Invest Dermatol 128: 1852-1860. [PubMed]

187. Rahim K (2017) Bacterial Contribution in Chronicity of Wounds. Microb Ecol

\section{3: 710-721. [PubMed]}

188. Mei SH (2010) Mesenchymal stem cells reduce inflammation while enhancing bacterial clearance and improving survival in sepsis. Am J Respir Crit Care Med 182: 1047-1057. [PubMed]

189. Arango-Rodriguez ML (2015) Could cancer and infection be adverse effects of mesenchymal stromal cell therapy?. World J Stem Cells 7: 408-417. [PubMed]

190. Meisel R (2011) Human but not murine multipotent mesenchymal stromal cells exhibit broad-spectrum antimicrobial effector function mediated by indoleamine 2.3-dioxygenase. Leukemia 25: 648-654.

191. Krasnodembskaya A (2010) Antibacterial effect of human mesenchymal stem cells is mediated in part from secretion of the antimicrobial peptide LL-37. Stem Cells 28: 2229-2238. [PubMed]

192. Galstyan GM (2015) Use of Mesenchymal Stromal Stem Cells for the Treatment of Sepsis. Anesteziol Reanimatol 60; 59-65. [PubMed]

193. Gonzalez-Rey E (2009) Human adult stem cells derived from adipose tissue protect against experimental colitis and sepsis. Gut 58: 929-939. [PubMed]

194. Lee JW (2013) Therapeutic effects of human mesenchymal stem cells in ex vivo human lungs injured with live bacteria. Am J Respir Crit Care Med 187: 751-760. [PubMed]

195. Curley JM (2014) Therapeutic potential and mechanisms of action of mesenchymal stromal cells for Acute Respiratory Distress Syndrome. Curr Stem Cell Res Ther 9: 319-329. [PubMed]

196. Sutton MT (2016) Antimicrobial Properties of Mesenchymal Stem Cells: Therapeutic Potential for Cystic Fibrosis Infection. and Treatment. Stem Cells Int 1: 5303048. [PubMed]

197. Mezey E (2015) Mesenchymal stem cells and infectious diseases: Smarter than drugs. Immunol Lett 168: 208-214. [PubMed]

198. Shin S (2013) The therapeutic effect of human adult stem cells derived from adipose tissue in endotoxemic rat model. Int J Med Sci 10: 8-18. [PubMed]

199.Zheng G (2014) Treatment of acute respiratory distress syndrome with allogeneic adipose-derived mesenchymal stem cells: a randomized. placebocontrolled pilot study. Respir Res 15: 39. [PubMed]

200.Sung DK (2016) Antibacterial effect of mesenchymal stem cells against Escherichia coli is mediated by secretion of beta- defensin- 2 via toll- like receptor 4 signalling. Cell Microbiol 18: 424-436. [PubMed]

201. Alcayaga-Miranda F (2015) Combination therapy of menstrual derived mesenchymal stem cells and antibiotics ameliorates survival in sepsis. Stem Cell Res Ther 6: 199. [PubMed]

202. Gupta N (2012) Mesenchymal stem cells enhance survival and bacteria clearance in murine Escherichia coli pneumonia. Thorax 67: 533-539.

203. Yang Y (2013) A subset of IL-17(+) mesenchymal stem cells possesses antiCandida albicans effect. Cell Res 23: 107-121. [PubMed]

204. Harman RM (2017) Antimicrobial peptides secreted by equine mesenchymal stromal cells inhibit the growth of bacteria commonly found in skin wounds. Stem Cell Res Ther 8: 157. [PubMed] 